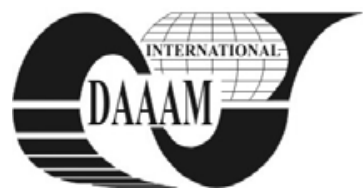

Annals of DAAAM for 2011 \& Proceedings of the 22nd International DAAAM Symposium, Volume 22, No. 1, ISSN 1726-9679 ISBN 978-3-901509-83-4, Editor B. Katalinic, Published by DAAAM International, Vienna, Austria, EU, 2011 Make Harmony between Technology and Nature, and Your Mind will Fly Free as a Bird Annals \& Proceedings of DAAAM International 2011

\title{
MILLING OF CAST MATERIAL AND PTA-HARD-FACING LAYERS OF THE COBALT-BASE-ALLOY STELLITE 12
}

\author{
HOESEL, D[anny]; WERTHEIM, R[afael]; HAENEL, T[homas] \& THURNER, S[tefan]
}

\begin{abstract}
Co-based alloys are used for highly stressed products such as dies and molds or machine components, mainly due to their resistance against wear, corrosion and heat. The coating of die and molds - similar to the regeneration by deposition welding - offers huge economic and technological potentials. The deposited layers fulfil the demands for tolerances and surface quality only partially so that a finishing process is essential. This study investigates the milling of cast and deposited Stellite 12 with different milling tools, cutting materials and machining parameters. The tool life in machining cast Stellite compared with deposited Stellite is much better, while the cutting edge geometry either double negative or negative/positive is optimized from case to case. Good results were achieved with CBN inserts under high speed cutting conditions. Key words: hard-facing, hard cutting, face milling, Co-based alloy, hardening effect
\end{abstract}

\section{INTRODUCTION}

The increasing complexity of highly stressed machined products such as dies and molds or machine components, combined with the demand for increased tool life requires the use of materials, which are more resistant against wear and high temperature. In addition, the ongoing demand for improving economic and ecological aspects makes it necessary to consider a change in the use of coating compositions and technologies for this type of application. The deposition of complete tools or partial deposits, similar to the regeneration of active surfaces by deposition of welded layers, offers huge economic and technological potentials. Nevertheless, the applied coating systems fulfil only partially the demands for measure-, form- and geometric tolerances as well as surface quality, so a finishing process by machining is essential. Co-based-alloys are typically wear-resistant materials, which are recommended under high mechanical and thermal stresses (Mennig \& Lake, 2008).

The finishing is normally done by the expensive and time consuming EDM or by grinding processes because of the specific properties and poor machinability of these alloys. Concerning machining with geometrically defined cutting edge, a number of investigations were carried out on turning, but only few publications include finishing by milling. This is necessary for the production of complex, free-form geometries in dies and molds. This paper presents the results of face milling investigations of cast and PTA-welded Stellite 12 with toric tools using round inserts of Cubic Boron Nitride (CBN) under various operation parameters.

\section{MATERIALS AND EXPERIMENTAL SETUP}

\subsection{Materials structure and properties}

The term "superalloys" summarizes a huge number of wear resistant materials. These are multicomponent systems, including high percentages of chromium and small amounts of metals with high melting temperatures such as molybdenum or tungsten (Schatt, 2003). The formed carbides or intermetallic phases are finely dispersed into the matrix of iron, nickel and cobalt based solid solution. Stellite 12 is a typical cobalt based alloy with a chemical composition of Co-Cr-W-C. Figure 1 shows micrographs of cast (left) and Plasma Trans Arc (PTA)-welded (right) Stellite 12. The hypoeutectic structure of this CoCr29W9C1.8 material solidified from a melt of Co-Cr-W matrix in a dendritic structure (Fig.1. left-1) with interdendritic lamellar morphology of the eutectic (Fig.1. left-2). The eutectic is formed with Co-phase and predominant $\mathrm{Cr}_{7} \mathrm{C}_{3}$ carbides. Obviously the cast specimen forms a considerably greater microstructure than the PTA-welded specimen. The finer grain structure of the PTA-welded Stellite 12 is a result of the higher cooling rate compared to the cooling rate of the cast material.

This has a significant influence on mechanical properties such as hardness and compressive strength. The macro hardness of cast Stellite 12 is approximately $450 \mathrm{HV} 5$ compared with 540 HV5 of the PTA-welded layer material. The compressive strength of the PTA-welded material with approximately $2090 \mathrm{~N} / \mathrm{mm}^{2}$ is also higher than that of the cast Stellite, which can only reach approximately $1720 \mathrm{~N} / \mathrm{mm}^{2}$. In terms of machining a coarse grain is more favourable. This can be explained by higher brittleness and lower toughness, which have a positive effect concerning reduced cutting forces and lower tendency to built up edge (Weißbach, 2007).
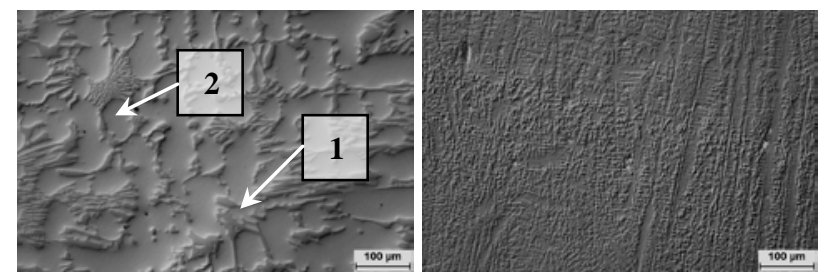

Fig. 1. Micrographs of cast Stellite 12 (left) and PTA-welded Stellite 12 (right) at the same level of optical magnification

\subsection{Experimental setup and procedure}

Due to limited experience in finish milling of these materials basic investigations were carried out on cast Stellite 12 . This base material exhibits good homogeneity and different mechanical properties compared with welded material as described in 2.1. Several geometrical specifications of cutting tools and inserts were used for the milling tests.

During the investigations, a toric milling tool with negative axial and radial rake angles, both with $-6^{\circ}$ and for comparison another toric tool with an axial rake angle of $+4^{\circ}$ and a radial rake angle of $-2^{\circ}$ were used. Basic milling experiments on cast Stellite 12 showed that CBN is suitable as a cutting tool material combining high hardness, relatively high toughness and chemical stability. Inserts made of SiC-whisker-reinforced ceramics and tungsten carbides proved to be inappropriate for milling with high cutting speeds. Only inserts with metal binder phase and a high percentage of CBN were convincing because of their better tool life. Therefore this cutting material was applied in the following experiments. The breadboard and the technological parameters are shown in Fig 2. 


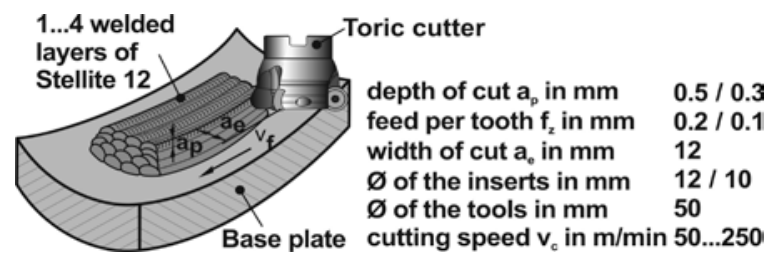

Fig. 2. Experimental setup and technological parameters

\section{RESULTS AND DISCUSSION}

The milling tests were carried out up to a wear land of $0.4 \mathrm{~mm}$. In Fig. 3 the results of the milling tests of the cast Stellite 12 are shown. The best tool life was reached using cutting speeds of $150 \mathrm{~m} / \mathrm{min}$ or higher. Especially the use of full face CBN insert with double negative angles, in Fig. 3 black, resulted in a larger milling length for even higher cutting speeds. Furthermore, a constant increase in flank wear and crater wear of both tool geometries should be noted. The differences between the measured forces during machining are significant. So in direct comparison the tool with the positive/negative rake angles induced 15 to 20 per cent lower cutting forces at a cutting speed of $150 \mathrm{~m} / \mathrm{min}$ and 20 to 30 per cent lower passive forces. Therefore, this geometrical specification is preferred with regard to the lower influence of surface integrity and the lower essential demand of energy.

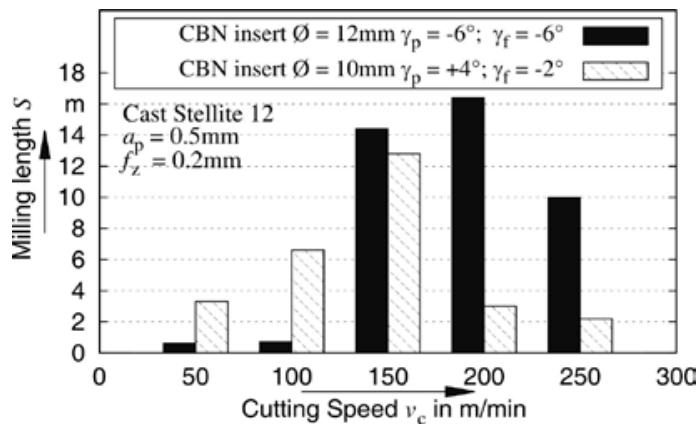

Fig. 3. Milling length with CBN inserts of cast Stellite 12

In milling of PTA-welded Stellite, a significantly shorter milling length due to chipping of the CBN inserts was achieved, as shown in Fig. 4. The reason for the shorter tool life is the difference in material properties. The $\mathrm{X}$-ray diffraction tests (XRD) revealed the difference between the cast and the PTA-welded Stellite 12. While the PTA-welded layer material exhibited only face-centred cubic lattice (fcc), the cast Stellite 12 showed, beside fcc structures, also hexagonal-close-packed (hcp) $\varepsilon$-martensite fractions. Because of the fine microstructure and the pure fcc-lattice, the welded material tends to generate stacking faults under plastic strain (Fouilland et.al, 2008).

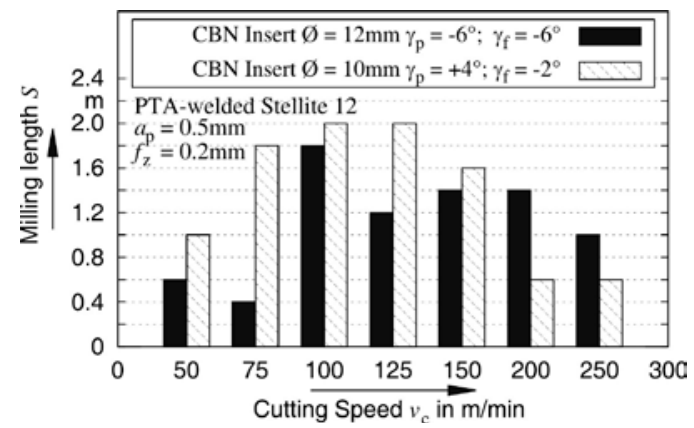

Fig. 4 Milling length with CBN inserts of welded Stellite 12

A change from fcc to hcp lattice could not be determined by $\mathrm{X}$-ray tests so it may be assumed that stacking faults are the reason for hardening as described in (Packeisen \& Thei- sen, 1999). The hardening zone could be measured to a depth of $0.14 \mathrm{~mm}$ (Fig. 5) and the top layer showed a rise in hardness of up to 700 HV5 and partially even up to 750 HV5.

Due to the work hardening effect caused by the cutting forces it became evident that a diametrical behaviour is present. With increasing tool wear higher forces are induced into the subsurface leading to an increase in the hardening effect. The surface hardening effect caused outbreaks of the cutting edge and had an extremely negative effect on tool life.

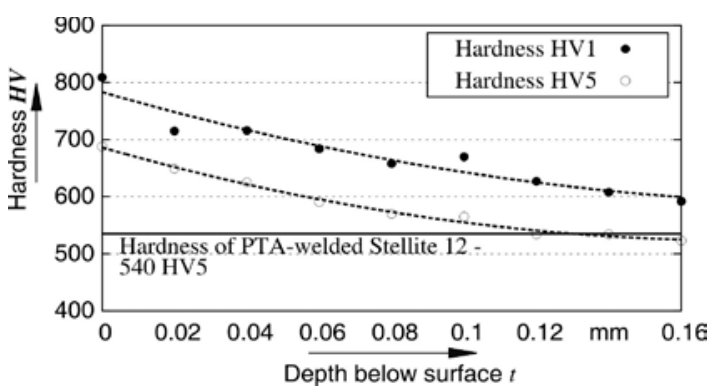

Fig. 5. Progress of hardness of machined PTA-welded layer

\section{CONCLUSIONS AND PERSPECTIVE}

This investigation shows that milling of Stellite 12 with CBN under high speed cutting conditions is possible. A double negative design of the cutting edge proves to be suitable for milling cast Stellite 12 with cutting speeds of more than $150 \mathrm{~m} / \mathrm{min}$ by a feed per tooth of $0.2 \mathrm{~mm}$. The cutting speed of $150 \mathrm{~m} / \mathrm{min}$ is also the optimal condition for using the positive/negative rake angles. The differences in the microstructures between cast and PTA-welded material are determining factors for the various milling lengths. A work induced hardening effect of the PTA-welded Stellite 12 is caused by the cutting forces during the milling process and reduced tool life and accelerated tool wear.

Further research regarding other geometrical specifications of the milling inserts should exhibit the influence on the hardening effect and achieve longer milling lengths. Additional investigations of various Stellite structures should prove the state of the subsurface after the milling process and their influence on wear resistance. The analysis of the influence of heattreatment is also a focus of future research.

\section{ACKNOWLEDGEMENTS}

The authors acknowledge the support of the ministry of education and research of Germany (BMBF), which initiated the research group "Auftragschichten". These results were developed within this framework.

\section{REFERENCES}

Fouilland, L.; El Mansori, M. \& Massaq, A. (2008), Frictioninduced work hardening of cobalt-base hardfacing deposits for hot forging tools, Journal of Materials Processing Technology - Volume 209 (2009), P. 3366-3373

Mennig G. \& Lake, M. (2008), Verschleiß in der Kunststoffverarbeitung. Phänomene und Schutzmaßnahmen, Hanser Fachbuchverlag, ISBN 978-3446156364

Packeisen, A. \& Theisen, W. (1999), Spanende Bearbeitung von Hartlegierungen - Drehen und Schleifen - Teil II, Drehen von Hartlegierungen, Materialswissenschaft und Werkstofftechnik 30 (1999), P. 208-220, WILEY-VCH Verlag

Schatt, W.; Simmchen, E. \& Zouhar, G. (2003), Konstruktionswerkstoffe des Maschinen- und Anlagenbaues, Deutscher Verlag für Grundstoffindustrie, ISBN: 978-352730955

Weißbach, W. (2007), Werkstoffkunde: Strukturen, Eigenschaften, Prüfung, 16., überarbeitete Auflage, Vieweg + Teubner Verlag, ISBN: 978-3834802958 